\title{
Level of Disability among Teachers of Superior University Lahore with Neck and/or Shoulder Pain
}

\author{
Arbab Zaheer ${ }^{1}$, Hira Jabeen ${ }^{2}$, Hafiz Sheraz Arshad \\ ${ }^{1}$ Physiotherapist, Azra Naheed Medical College, Department of Physical Therapy, Main Raiwind Road Lahore \\ ${ }^{2}$ Senior lecturer, Azra Naheed Medical College, Department of Physical Therapy, Main Raiwind Road, Lahore \\ ${ }^{3}$ Assistant Professor, Azra Naheed Medical College, Department of Physical Therapy, Main Raiwind Road, Lahore
}

\begin{abstract}
In developed or developing countries the most common health issue is musculoskeletal disorder. Neck and/or shoulder pain in working population such as in Teachers is increasing day by day. The objective of this study is to determine the level of disability among the teachers of Superior University Lahore with neck and/or shoulder pain. A descriptive cross sectional study comprises of 98 teachers of superior university with neck and/or shoulder pain. This study results that neck pain is more common in teachers of superior university Lahore than shoulder pain and there is moderate disability due to neck pain and mild disability due to shoulder pain.
\end{abstract}

Keywords: Disability, Musculoskeletal disorders, Neck pain, Shoulder pain, Teachers

\section{Introduction}

\subsection{Overview}

In developed or developing countries the most common health issue is musculoskeletal disorder. Neck and/or shoulder pain in working population such as in Teachers is increasing day by day. Incidence of shoulder pain is $73.4 \%$ and neck pain is $68.9 \%$. Factors responsible for it is increasing age, gender, working duration, and poor or improper posture[1]. Shoulder pain or neck pain is very common in our population. In $48.7 \%$ of school teachers responsible for shoulder pain in teacher's on the other hand low back pain also occur in teachers about 40\%-70\%. Upper extremity is more painful in teachers because of excessive load and stress. These factors include static posture, hypertension, excessive loading, computer use, stress and psychological issues[2].Neck and Shoulder pain increasing day by day in teachers that result in occupational, mental and physical disability under the age of 45 or more the musculoskeletal disorder results in occupational and physcological impairment. It was found that severe neck pain or shoulder pain result in loss of activities such as loss in picking or grasping objects and loss of ADL and IADL's .Daily heavy duty, work or lifting cause neck and/or shoulder pain[3].Neck pain or shoulder pain results discomfort and anxiety that leads to increased number of leaves of teachers from their working places. Although it was clear that working population is more prone to have neck pain, frequency between them was not static and ranged between $23.7 \%$ and $95.1 \%$. Musculoskeletal pain start from minor aches, discomfort, vertigo and then lead to serious condition if not treated at time. In severe cases recovery from musculoskeletal pain and trauma is incomplete [4].Deep cervical flexors muscles are important muscles of neck and head these muscles provide stability and protection to neck any disturbance, injury, trauma to these muscles result in neck and shoulder disability .Neck pain is not only a problem for older peoples but now it become a problem for youngster.
Prolonged neck flexion may result in increase forces or compression on cervical spine that affect the bones or nerves of spine and causes discomfort and disturb the daily routine of teaching[5].Musculoskeletal pain decrease the rate of work, job duration and result in early retirement. Musculoskeletal pain depend upon a type of job what you are doing, due to heavy duty or excessive work of teaching leads to stress which effect the mental health of teachers. Teachers mostly use head down posture during checking or studying the papers. Teachers participate in extracurricular activities as well. Neck and shoulder pain in teachers may be caused by poor knowledge about posture[6].Poor posture leads to stress which will affect performance of teaching[4].This research has not been conducted before. All the previous studies include musculoskeletal problems other than shoulder and neck pain in university teachers. Previous studies investigated the frequency of musculoskeletal disorders among school teachers but I am going to study level of disability among teachers of superior university Lahore with neck and/or shoulder pain. The reason of study to analyze the level of disability in Superior university teachers with neck and/or shoulder pain. Superior university teachers are only focused in this study.

\subsection{Objective}

The objective of this study is to determine the level of disability among Teachers of Superior University Lahore with Neck and/or Shoulder pain.

\subsection{Rationale}

This study will help to decrease the level of disability among teachers of superior university Lahore, with neck and/or shoulder pain by addressing the key issues present in posture. It will improve the quality of life among teachers of Superior University Lahore.

\subsection{Operational definition}

\subsubsection{Neck disability index}

A self reporting questionnaire used to assess the patients with neck pain and how neck pain affects its daily activities. 


\section{International Journal of Science and Research (IJSR) \\ ISSN (Online): 2319-7064 \\ Index Copernicus Value (2013): 6.14 | Impact Factor (2015): 6.391}

Its test retest reliability is $0.94-0.98$, internal consistency is $0.90-0.96$, and validity is $0.64-0.8[7]$

\subsubsection{Shoulder pain and disability index}

A shoulder pain and disability index is used to measure the disability and pain associated with any kind of pathology of shoulder. Its tests retest reliability is 0.63-0.65 and internal consistency is $0.86-0.95$ [8].

\subsection{Material and Methods}

\subsubsection{Study Design}

This study was descriptive (cross sectional study).

\subsubsection{Duration}

This study was completed in estimated period of 3 months after the approval from ANMC research committee.

\subsubsection{Setting}

The study was conducted in Superior University Lahore

\subsubsection{Sample Size}

The Sample size of this research was be 98 .The sample size was calculated by the software Rao-soft sample size calculator. 5\% margin of error with a 95\% confidence level was used to calculate the sample size. $85 \%$ response rate will be expected.

According to following formula

$\mathrm{x}=\mathrm{Z}(\mathrm{c} / 100) 2 \mathrm{r}(100-\mathrm{r})$

$\mathrm{n}=\mathrm{N} x /((\mathrm{N}-1) \mathrm{E} 2+\mathrm{x})$

$\mathrm{E}=\operatorname{Sqrt}[(\mathrm{N}-\mathrm{n}) \mathrm{x} / \mathrm{n}(\mathrm{N}-1)]$

$(N)=$ used for population Size

$(E)=$ for margin error

$\mathrm{Z}(\mathrm{c} / 100)=$ value for confidence level.

\subsubsection{Sampling Technique}

Simple random sampling technique

\subsubsection{Sample Selection}

\subsubsection{Inclusion criteria}

- Superior university Lahore.

- Male and female both teachers

- Working hours at least 6 hours daily.

- Teachers with the Age: 25-40 years

\subsubsection{Exclusion criteria}

- Any trauma, injury or surgery of neck and shoulder.

- Any other musculoskeletal deformity.

- Cardiac, thoracic surgery and systemic disease.

\subsubsection{Data collection procedure}

All 98 Teachers of Superior University Lahore fulfilling the inclusion criteria were selected. The data collection procedure is done by using a neck disability index questionnaire and shoulder pain and disability index. I collect data after an informed consent, (i.e.-I will tell about the aims and objectives of my study verbally to subject and I will ensure the subjects for confidentiality) from subject and by giving questionnaire to teachers of superior university Lahore, Pakistan. As this questionnaire is used to find out the neck and shoulder pain so by this way, I collected data from teachers of Superior University Lahore.

\subsubsection{Participants Rights}

The ethical approval was taken by the Superior university from where the data was supposed to be collected. Informed consent was given to all participant and all data will remain confidential. There is no negative consequence of this research.

\section{Results}

Table 1: Frequency distribution of Gender

\begin{tabular}{|c|c|c|}
\hline & Frequency & \%age \\
\hline Male & 56 & 57.1 \\
\hline Female & 42 & 42.9 \\
\hline
\end{tabular}

The majority of teachers were males $(57.1 \%)$.

Table 2: Frequency distribution of Age

\begin{tabular}{|c|c|c|}
\hline Age & Frequency & \%age \\
\hline $25-30$ & 59 & 60.2 \\
\hline $31-35$ & 38 & 38.8 \\
\hline $36-40$ & 1 & 1.0 \\
\hline
\end{tabular}

It was reported maximum age of teachers participated in this study was between 25-30 years and minimum age was between $36-40$ years.

Table 3: Frequency distribution of teaching experience, working hours, sitting hours, standing hours and computer use

\begin{tabular}{|c|c|c|c|}
\hline & Minimum & Maximum & Mean \pm SD \\
\hline Teaching experience & 1 & 9 & $3.91 \pm 2.0$ \\
\hline Working hours & 6 & 12 & $8.08 \pm 0.87$ \\
\hline Sitting hours & 1 & 7 & $3.76 \pm 1.16$ \\
\hline Standing hours & 1 & 10 & $3.83 \pm 1.34$ \\
\hline Computer use & 1 & 6 & $2.46 \pm 1.12$ \\
\hline
\end{tabular}

Table 4: Descriptive statistics of Neck disability index

\begin{tabular}{|c|c|c|c|}
\hline & Minimum & Maximum & Mean \pm SD \\
\hline SCORE NDI & 4 & 32 & $20.79 \pm 4.37$ \\
\hline
\end{tabular}

Its mean was 20.79 and this shows moderate neck disability in teachers of superior university Lahore

Table 5: Descriptive statistics of pain and disability scale score

\begin{tabular}{|c|c|c|c|}
\hline & Mean \pm SD & Minimum & Maximum \\
\hline Pain scale score & $20.96 \pm 6.91$ & 2 & 36.00 \\
\hline Disability scale score & $14.0 \pm 5.0$ & 3 & 28 \\
\hline
\end{tabular}

$* \mathrm{SD}=$ standard deviation

Total Mean score for pain scale was 20.96(SD=6.91) Minimum score was 2 and Maximum score was 36.00. Total Mean for disability scale score was 14.0 ( $\mathrm{SD}=5.0)$ Minimum score was 3 and Maximum score was 28 .

Table 6: Descriptive statistics of SPADI score

\begin{tabular}{|c|c|c|c|}
\hline & Mean \pm SD & Minimum & Maximum \\
\hline Total SPADI score & $16.68 \pm 5.03$ & 5 & 28 \\
\hline
\end{tabular}

$* \mathrm{SD}=$ standard deviation

Total Mean score for shoulder pain and disability index (SPADI) was 16.68 (SD=5.03) Maximum value was 28 and Minimum value was 5 .

\section{Volume 5 Issue 6, June 2016 www.ijsr.net}




\section{International Journal of Science and Research (IJSR) \\ ISSN (Online): 2319-7064 \\ Index Copernicus Value (2013): 6.14 | Impact Factor (2015): 6.391}

Table 7: Descriptive statistics for responses of individual items of pain scale

\begin{tabular}{|l|c|}
\hline & Mean \pm SD \\
\hline At its worst? & $2.08 \pm .85$ \\
\hline When lying on the involved side? & $2.08 \pm .87$ \\
\hline Reaching for something on a high shelf? & $2.23 \pm .87$ \\
\hline Touching the back of your neck? & $2.07 \pm .84$ \\
\hline Pushing with the involved arm? & $2.01 \pm .83$ \\
\hline
\end{tabular}

$* \mathrm{SD}=$ standard deviation

On individual items of pain scale the highest rated item in severity was "reaching for something on a high shelf" (Mean $\pm \mathrm{SD}=2.23 \pm .87$ ) followed by "when lying on the involved side" $(\mathrm{Mean} \pm \mathrm{SD}=2.08 \pm .87)$.

\section{Conclusion}

This study concludes that the teachers of superior university Lahore experienced moderate level of disability because of neck pain and mild level of disability due to shoulder pain. . This study shows that neck and shoulder pain may cause disability and affect the lifestyle of teachers.

\section{Discussion}

This research was done for evaluating the level of disability among teachers of superior university Lahore with neck and/or shoulder pain.

In one research most of the teachers have more than 5 years teaching experience. The result showed that many health issues related to teachers .This study arouse awareness in community that stress is not only common in teachers many other health issues were common in teachers like musculoskeletal pain.[6]

In previous study it was concluded that neck and shoulder pain is less in males than female. This study identifies that neck and/or shoulder pain was more prevalent than low back pain in different school teachers of china. Many strategies are requires to solve this problem in teachers. [1]

In another study it was concluded that number of teaching year is main important risk factor of musculoskeletal pain and incidence of musculoskeletal pain in female teachers of secondary school is high because of age factor, type of teaching, excessive weight.[4]

A longitudinal study reported that neck and shoulder pain is more common in secondary or primary school teachers. A number of limitations were found in this study. This study has no restriction on age, working hours and experience. This study include nursery, primary, secondary school teachers and teachers having mentally and physically retarded children. [9]

A cross sectional survey was done in teachers of Turkey. In this study copping strategies were assessed by teachers. Poor posture, prolonged standing and age were the most important risk factors. In many teachers neck and/or shoulder pain is severe enough that they were need pain killers and teachers were also absent from their work. [3]
A systematic review study reported that there were a relationship between poor posture and neck pain. This study only emphasis the risk factors of neck pain mostly poor or impaired posture leading to neck pain.[10]

The results of this study were based on teachers of superior university Lahore. The study was based on self administrated questionnaire so most of times the teachers may have given answer to please the researcher. And teachers were having shortage of time so they filled the questionnaire in hurry.Hence, neck and/or shoulder pain does affect teacher's life in a negative way and had reduced their interest in communicating and deliver lectures to students and being punctuate for university. Health programs are necessary for their motivation and cooperation of the doctor is recommended.

\section{References}

[1] YUE, P., LIU, F. \& LI, L. 2012. Neck/shoulder pain and low back pain among school teachers in China, prevalence and risk factors. BMC Public Health, 12, $1471-2458$

[2] ABDULMONEM, A., HANAN, A., ELAF, A., HANEEN, T. \& JENAN, A. 2014. The prevalence of musculoskeletal pain \& its associated factors among female Saudi school teachers. Pak J Med Sci, 30, 11916.

[3] KORKMAZ, N. C., CAVlaK, U. \& TELCI, E. A. 2011. Musculoskeletal pain, associated risk factors and coping strategies in school teachers. Scientific Research and Essays, 6, 649-657.

[4] DARWISH, M. A. \& AL-ZUHAIR, S. Z. 2013. Musculoskeletal Pain Disorders among Secondary School Saudi Female Teachers. Pain Res Treat, 878570, 22.

[5] IQBAL, Z. A., RAJAN, R., KHAN, S. A. \& ALGHADIR, A. H. 2013. Effect of deep cervical flexor muscles training using pressure biofeedback on pain and disability of school teachers with neck pain. $J$ PhysTherSci, 25, 657-61.

[6] CHONG, E. Y. L. \& CHAN, A. H. S. 2010. Subjective Health Complaints of Teachers From Primary and Secondary Schools in Hong Kong. International Journal of Occupational Safety and Ergonomics, 16, 23-39.

[7] VERNON, H. \& MIOR, S. 1991. The Neck Disability Index: a study of reliability and validity. J Manipulative Physiol Ther, 14, 409-15.

[8] ROACH, K. E., BUDIMAN-MAK, E., SONGSIRIDEJ, N. \& LERTRATANAKUL, Y. 1991. Development of a shoulder pain and disability index. Arthritis \& Rheumatism, 4, 143-149.

[9] ERICK, P. N. \& SMITH, D. R. 2011. A systematic review of musculoskeletal disorders among school teachers. BMC musculoskeletal disorders, 12, 260.

[10]ARIENS, G. A., VAN MECHELEN, W., BONGERS, P. M., BOUTER, L. M. \& VAN DER WAL, G. 2000. Physical risk factors for neck pain.Scandinavian journal of work, environment \& health, 7-19. 


\section{International Journal of Science and Research (IJSR)}

ISSN (Online): 2319-7064

Index Copernicus Value (2013): 6.14 | Impact Factor (2015): 6.391

\section{Author Profile}

ArbabZaheer is Physical therapist, Azra Naheed Medical College,

Department of Physical Therapy, Main Raiwind Road, Lahore

HiraJabeen is Senior Lecturer, Azra Naheed Medical College,

Department of Physical Therapy, Main Raiwind Road, Lahore

Hafiz SherazArshad is Head of department/Assistant professor, Azra Naheed Medical College, Department of Physical Therapy, Main Raiwind Road, Lahore

Volume 5 Issue 6, June 2016 www.ijsr.net 